Article

\title{
Synthesis and Biological Evaluation of Novel 10-Substituted-7- ethyl-10-hydroxycamptothecin (SN-38) Prodrugs
}

\author{
Mo Zhou ${ }^{1, \dagger}$, Meixia Liu ${ }^{1, \dagger}$, Xinhua He ${ }^{1}$, Hong Yu ${ }^{2}$, Di Wu ${ }^{3}$, Yishan Yao ${ }^{1}$, Shiyong Fan ${ }^{1}$, \\ Ping Zhang ${ }^{1}$, Weiguo Shi ${ }^{1, *}$ and Bohua Zhong ${ }^{1, *}$
}

1 Beijing Institute of Pharmacology \& Toxicology, 27 Tai-Ping Road, Beijing 100850, China; E-Mails: michelle_zm2011@163.com (M.Z.); liumeixia@163.com (M.L.); hexinhua01@163.com (X.H.); spray_yao123456@hotmail.com(Y.Y.); fsyn1996@163.com (S.F.); gundnir@163.com (P.Z.)

2 Cell Biology Laboratory of Jilin Province Tumor Institute, No 1018 Huguang Road, Changchun 130012, China; E-Mail: yuhong123@163.com

3 Tumor Centre, No.1 Hospital, Jilin University, 71 Xin-Min Street, Changchun 130012, China; E-Mail:wd78@163.com

$\dagger$ These authors contributed equally to this work.

* Authors to whom correspondence should be addressed;

E-Mails: bohuazhong0501@163.com (B.Z.); shiwg1988@126.com (W.S.);

Tel.: +86-10-6693-1639 (B.Z.); +86-10-6687-4612 (W.S.); Fax: +86-10-6821-1656 (B.Z. \& W.S.).

External Editor: Jean Jacques Vanden Eynde

Received: 29 October 2014; in revised form: 19 November 2014 / Accepted: 19 November 2014 / Published: 27 November 2014

\begin{abstract}
In an attempt to improve the antitumor activity and reduce the side effects of irinotecan (2), novel prodrugs of SN-38 (3) were prepared by conjugating amino acids or dipeptides to the 10-hydroxyl group of SN-38 via a carbamate linkage. The synthesized compounds completely generated SN-38 in pH 7.4 buffer or in human plasma, while remaining stable under acidic conditions. All prodrug compounds demonstrated much greater in vitro antitumor activities against HeLa cells and SGC-7901 cells than irinotecan. The most active compounds, $\mathbf{5 h}, \mathbf{7 c}, \mathbf{7 d}$, and $\mathbf{7 f}$, exhibited $\mathrm{IC}_{50}$ values that were 1000 times lower against HeLa cells and 30 times lower against SGC-7901 cells than those of irinotecan, and the inhibitory activities of these prodrugs against acetylcholinesterase (AchE) were significantly reduced, with $\mathrm{IC}_{50}$ values more than 6.8 times greater than that of irinotecan. In
\end{abstract}


addition, compound 5e exhibited the same level of tumor growth inhibitory activity as irinotecan (CPT-11) in a human colon xenograft model in vivo.

Keywords: antitumor agent; camptothecins; prodrugs; SN-38

\section{Introduction}

Camptothecin (CPT 1, Figure 1) derivatives are potent topoisomerase I inhibitors with strong antitumor activities both in vitro and in vivo and are the only antitumor agents with topoisomerase I inhibitory activity used in the clinic [1,2].

Figure 1. Structure of camptothecin and its analogs.
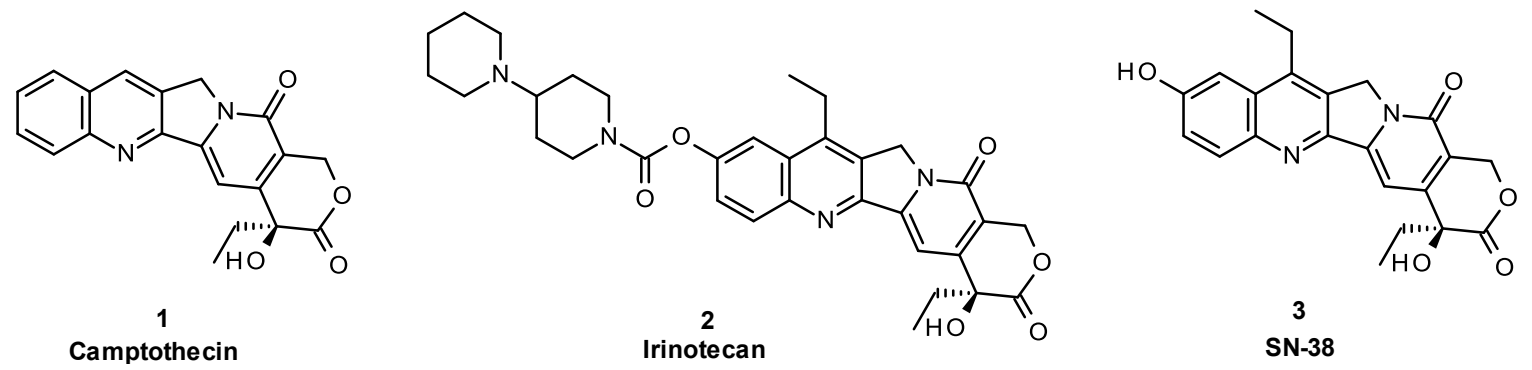

Irinotecan (2) is a water-soluble prodrug of CPT derivative SN-38 (3). It is the most widely used CPT derivative for the treatment of colorectal cancer that has been previously treated with 5-fluorouracil; in addition, it has activity against a wide range of other cancers either as a single agent or in combination with other antitumor agents [3-6]. However, high individual variation in efficacy and toxicity as well as side effects, including acute cholinergic diarrhea, preclude its clinical use. It is believed that the low bioconversion efficiency ( $4 \%-5 \%$ ) from irinotecan to the active form $\mathrm{SN}-38$ is responsible for high interpatient variability in terms of the pharmacokinetics, which leads to considerable individual variation in efficacy and toxicity [7-9]. Moreover, the 4-piperidinopiperidine moiety of irinotecan is responsible for inhibiting acetylcholinesterase (AChE) activity, causing acute cholinergic diarrhea [10-12].

In this study, novel water soluble prodrugs of SN-38, with reduced AChE inhibitory activity, that could be completely converted to SN-38 were designed and synthesized. Linear amino acids or dipeptides with less steric effects were used to replace the 4-piperidinopiperidine moiety of irinotecan. Firstly, amino acids are considered to have well physiological compatibility and ability to penetrate the biological membrane by active transport, which make them the ideal prodrug carriers. Secondly, the carboxyl groups(-COOH) in amino acids or dipeptides can be easily converted to sodium or potassium salt to improve water solubility of prodrugs. The target compounds were prepared by conjugating an amino acid or dipeptide to the 10-hydroxyl group of SN-38 via a carbamate linker.

These prodrugs were stable in aqueous solutions at acidic $\mathrm{pH}$ levels but were rapidly converted to active SN-38 in pH 7.4 buffer or in human plasma (Figure 2). These new CPT prodrugs exhibited much greater antitumor activity and less AChE inhibitory activity than irinotecan in vitro. 
Figure 2. Conversion of target compound to SN-38.
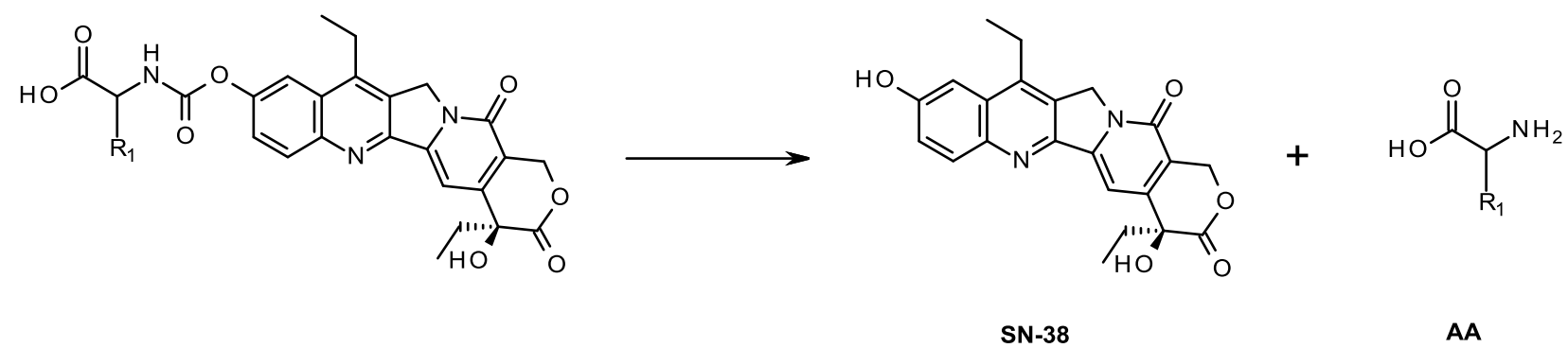

\section{Results and Discussion}

\subsection{Chemistry}

The synthesis of the prodrugs is shown in Scheme 1. The benzyl ester of the amino acid was initially converted in good yield to the corresponding isocyanate in the presence of bis(trichloromethyl) carbonate. Next, the isocyanate was reacted with SN-38 to give coupled compounds 4 in $83 \%-89 \%$ yield. Deprotection of $\mathbf{4}$ by catalytic hydrogenation yielded compounds $\mathbf{5 a}-\mathbf{h}$.

Scheme 1. Synthesis of prodrugs 5a-h.
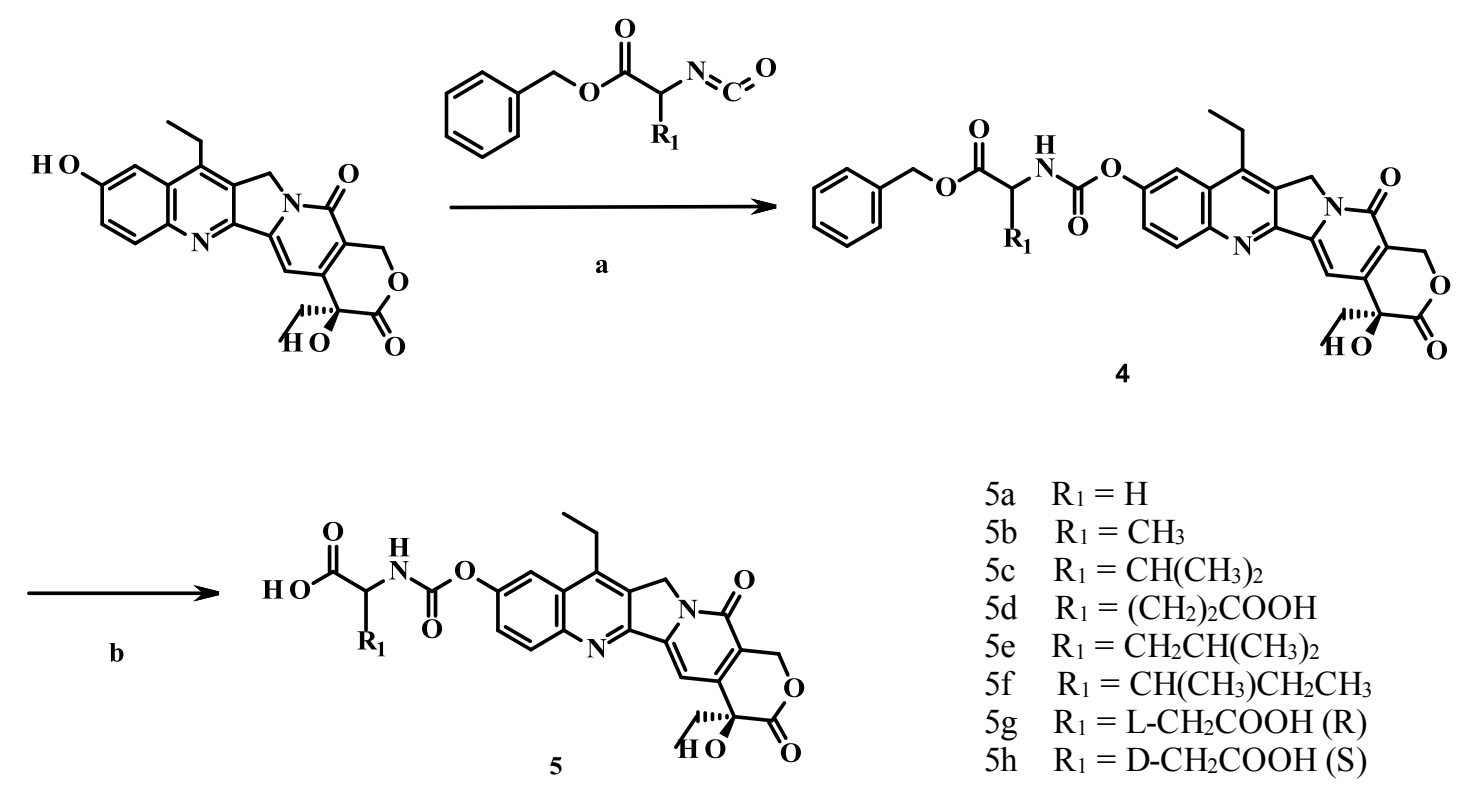

Reagents and conditions: (a) (i) $\mathrm{Et}_{3} \mathrm{~N}$, THF, rt, $30 \mathrm{~min}$; (ii) isocyanate, $\mathrm{THF}, 40{ }^{\circ} \mathrm{C}$, overnight;

(b) $\mathrm{Pd} / \mathrm{C}, \mathrm{H}_{2}, \mathrm{THF} / \mathrm{EtOH}$, rt, overnight.

Next, the dipeptide derivatives $7 \mathbf{a}-\mathbf{f}$ were synthesized by further conjugating the amino acid derivatives 5 with another amino acid in THF under room temperature for $24 \mathrm{~h}$, as depicted in Scheme 2. 
Scheme 2. Synthesis of prodrugs $7 \mathbf{a}-\mathbf{f}$.
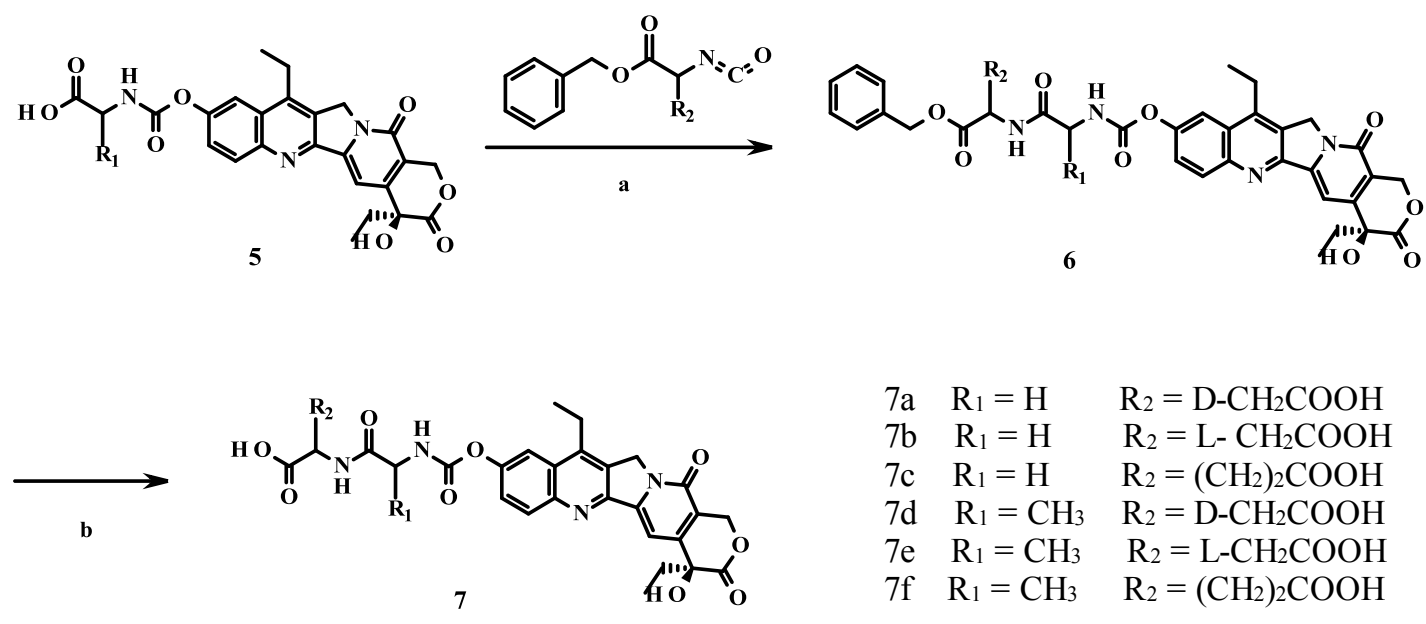

$$
\begin{array}{lll}
7 \mathrm{a} & \mathrm{R}_{1}=\mathrm{H} & \mathrm{R}_{2}=\mathrm{D}-\mathrm{CH}_{2} \mathrm{COOH} \\
7 \mathrm{~b} & \mathrm{R}_{1}=\mathrm{H} & \mathrm{R}_{2}=\mathrm{L}-\mathrm{CH}_{2} \mathrm{COOH} \\
7 \mathrm{c} & \mathrm{R}_{1}=\mathrm{H} & \mathrm{R}_{2}=\left(\mathrm{CH}_{2}\right)_{2} \mathrm{COOH} \\
7 \mathrm{~d} & \mathrm{R}_{1}=\mathrm{CH}_{3} & \mathrm{R}_{2}=\mathrm{D}-\mathrm{CH}_{2} \mathrm{COOH} \\
7 \mathrm{e} & \mathrm{R}_{1}=\mathrm{CH}_{3} & \mathrm{R}_{2}=\mathrm{L}-\mathrm{CH}_{2} \mathrm{COOH} \\
7 \mathrm{f} & \mathrm{R}_{1}=\mathrm{CH}_{3} & \mathrm{R}_{2}=\left(\mathrm{CH}_{2}\right)_{2} \mathrm{COOH}
\end{array}
$$

Reagents and conditions: (a) (i) $\mathrm{Et}_{3} \mathrm{~N}$, THF, rt, $30 \mathrm{~min}$; (ii) isocyanate, $\mathrm{THF}, 40{ }^{\circ} \mathrm{C}$, overnight; (b) $\mathrm{Pd} / \mathrm{C}, \mathrm{H}_{2}, \mathrm{THF} / \mathrm{EtOH}$, rt, overnight.

\subsection{Cytotoxicity}

The in vitro antitumor activities were evaluated on human cancer cell lines SGC-7901 and HeLa by the MTT assay, using irinotecan as the reference compound. The results are summarized in Table 1. The prodrugs $\mathbf{5 a}-\mathbf{h}$ and $7 \mathbf{a}-\mathbf{f}$ all exhibited much more potent antiproliferative activities against HeLa cells than irinotecan. Compounds $\mathbf{5 e - 5 h}$ and $\mathbf{7 b}-\mathbf{7 f}$ also showed greater antitumor activities against SGC-7901 cells than irinotecan. The most active compounds $\mathbf{5 h}, \mathbf{7 c}, \mathbf{7 d}$, and $\mathbf{7 f}$ exhibited $\mathrm{IC}_{50}$ values that were less

\begin{tabular}{|c|c|c|c|}
\hline \multirow{2}{*}{ Compound } & \multirow{2}{*}{$\mathbf{R}_{1}$} & \multicolumn{2}{|c|}{$\mathrm{IC}_{50}(\boldsymbol{\mu M})$} \\
\hline & & SGC-7901 & HeLa \\
\hline $5 \mathbf{a}$ & $\mathrm{H}$ & $2.69 \pm 0.11$ & $(30.4 \pm 47.0) \times 10^{-3}$ \\
\hline $5 \mathbf{b}$ & $\mathrm{CH}_{3}$ & $1.75 \pm 0.60$ & $(9.85 \pm 11.1) \times 10^{-3}$ \\
\hline $5 c$ & $\mathrm{CH}\left(\mathrm{CH}_{3}\right)_{2}$ & $1.88 \pm 0.72$ & $(5.61 \pm 40.3) \times 10^{-3}$ \\
\hline $5 e$ & $\mathrm{CH}_{2} \mathrm{CH}\left(\mathrm{CH}_{3}\right)_{2}$ & $0.50 \pm 0.19$ & $(1.82 \pm 64.6) \times 10^{-3}$ \\
\hline $5 f$ & $\mathrm{CH}\left(\mathrm{CH}_{3}\right) \mathrm{CH}_{2} \mathrm{CH}_{3}$ & $0.76 \pm 0.34$ & $(3.64 \pm 1.03) \times 10^{-3}$ \\
\hline $5 g$ & $\mathrm{CH}_{2} \mathrm{COOH}(\mathrm{R})$ & $0.98 \pm 0.05$ & $(9.07 \pm 33.2) \times 10^{-3}$ \\
\hline $5 \mathbf{h}$ & $\mathrm{D}-\mathrm{CH}_{2} \mathrm{COOH}(\mathrm{S})$ & $0.24 \pm 0.95$ & $<(3.20 \pm 64.3) \times 10^{-3}$ \\
\hline Irinotecan & & $7.38 \pm 1.24$ & $1.32 \pm 0.13$ \\
\hline
\end{tabular}
than $3.2 \mathrm{nM}$ against HeLa cells, providing an approximately 1000-fold increase in potency compared to irinotecan. Meanwhile, they all showed antiproliferative activity that was 30-fold greater than that of irinotecan against SGC-7901 cells. Compared with the amino acid derivatives, the dipeptide derivatives exhibited greater antitumor activities.

Table 1. Antiproliferative activities of the derivatives against human cancer cell lines. 
Table 1. Cont.

\begin{tabular}{|c|c|c|c|c|}
\hline \multirow{2}{*}{ Compound } & \multirow{2}{*}{$\mathbf{R}_{1}$} & \multirow{2}{*}{$\mathbf{R}_{\mathbf{2}}$} & \multicolumn{2}{|c|}{$\mathrm{IC}_{50}(\boldsymbol{\mu M})$} \\
\hline & & & SGC-7901 & HeLa \\
\hline $7 a$ & $\mathrm{H}$ & D- $\mathrm{CH}_{2} \mathrm{COOH}$ & $1.04 \pm 0.90$ & $<(3.20 \pm 12.0) \times 10^{-3}$ \\
\hline $7 b$ & $\mathrm{H}$ & $\mathrm{L}-\mathrm{CH}_{2} \mathrm{COOH}$ & $0.61 \pm 0.68$ & $(14.8 \pm 135.0) \times 10^{-3}$ \\
\hline $7 \mathrm{c}$ & $\mathrm{H}$ & $\left(\mathrm{CH}_{2}\right)_{2} \mathrm{COOH}$ & $0.20 \pm 0.07$ & $<(3.20 \pm 0.40) \times 10^{-3}$ \\
\hline 7d & $\mathrm{CH} 3$ & $\mathrm{D}-\mathrm{CH}_{2} \mathrm{COOH}$ & $0.26 \pm 0.64$ & $<(3.20 \pm 2.0) \times 10^{-3}$ \\
\hline $7 e$ & $\mathrm{CH} 3$ & $\mathrm{~L}-\mathrm{CH}_{2} \mathrm{COOH}$ & $0.21 \pm 0.55$ & $(12.9 \pm 133.0) \times 10^{-3}$ \\
\hline $7 f$ & $\mathrm{CH} 3$ & $\left(\mathrm{CH}_{2}\right)_{2} \mathrm{COOH}$ & $0.27 \pm 0.18$ & $(1.57 \pm 3.10) \times 10^{-3}$ \\
\hline Irinotecan & & & $7.38 \pm 1.24$ & $1.32 \pm 0.13$ \\
\hline
\end{tabular}

\subsection{AChE Inhibition Assay}

Irinotecan has been reported to be a potent inhibiter of $\mathrm{AChE}$, and inhibition of this enzyme causes acute cholinergic diarrhea. Unlike irinotecan, the compounds we assayed were only weak inhibitors of AChE. As shown in Table 2, the $\mathrm{IC}_{50}$ value of irinotecan is $0.2 \mu \mathrm{M}$, while compounds $\mathbf{5 a}, \mathbf{5 f}, \mathbf{5 g}, \mathbf{5 h}, \mathbf{7 a}$, $\mathbf{7 c}, 7 \mathbf{d}$, and $7 \mathbf{f}$ exhibited $\mathrm{IC}_{50}$ values greater than $1.36 \mu \mathrm{M}$. One possible explanation is that the active site of AChE is present at the bottom of a gorge that is lined with hydrophobic amino acid residues [13]. The terminal dipiperidino moiety in CPT-11 that interacts with amino acid residues within AChE plays a major role in enzyme inhibition, which has been confirmed by X-ray crystallographic studies [14]. Hence, the hydrophobic side chain moiety of isoleucine in $\mathbf{5} \mathbf{f}$ was attracted into the gorge where catalysis occurs, while the others with hydrophilic moiety had a lower binding affinity with it.

Table 2. AChE inhibitory activity.

\begin{tabular}{cccc}
\hline Compound & IC $_{\mathbf{5 0}}(\boldsymbol{\mu M})$ & Compound & $\mathbf{I C}_{\mathbf{5 0}}(\boldsymbol{\mu M})$ \\
\hline $\mathbf{5 a}$ & 19.79 & $\mathbf{7 c}$ & $>100$ \\
$\mathbf{5 f}$ & 1.36 & $\mathbf{7 d}$ & 4.44 \\
$\mathbf{5 g}$ & 3.08 & $\mathbf{7 f}$ & 36.08 \\
$\mathbf{5 h}$ & 7.43 & Irinotecan & 0.20 \\
$\mathbf{7 a}$ & 115.7 & & \\
\hline
\end{tabular}

\subsection{Stability and Conversion}

The chemical stability of the prodrugs at $\mathrm{pH} 4.6$ or 7.4 in PBS at $37^{\circ} \mathrm{C}$ is summarized in Table 3 . All the target compounds showed $\mathrm{pH}$-dependent stability. They were stable at $\mathrm{pH} 4.6$ at $37{ }^{\circ} \mathrm{C}$ for $12 \mathrm{~h}$. Except for compound $\mathbf{5 h}$, less than $35 \%$ of the prodrugs remained after incubation for $12 \mathrm{~h}$ in $\mathrm{pH} 7.4$ buffer. The dipepetide derivatives $\mathbf{7 a}-\mathbf{f}$ showed much less stability than the amino acid derivatives $\mathbf{5 a}-\mathbf{h}$. For example, less than $30 \%$ of the prodrugs $7 \mathbf{a}-\mathbf{f}$ remained, while more than $85 \%$ of the prodrugs $\mathbf{5 a}-\mathbf{h}$ remained after incubation for $1 \mathrm{~h}$ in $\mathrm{pH} 7.4$ buffer. 
Table 3. The chemical stability of the prodrugs in $\mathrm{pH} 4.6$ and $\mathrm{pH} 7.4$ conditions.

\begin{tabular}{cccccc}
\hline & \multicolumn{3}{c}{ Remaining Prodrugs (\%) } \\
\cline { 2 - 3 } Compound & \multicolumn{2}{c}{$\mathbf{1} \mathbf{h}$} & & \multicolumn{2}{c}{$\mathbf{1 2} \mathbf{~ h}$} \\
\cline { 2 - 3 } \cline { 5 - 6 } & $\mathbf{p H ~ 4 . 6}$ & $\mathbf{p H ~ 7 . 4}$ & & $\mathbf{p H ~ 4 . 6}$ & $\mathbf{p H ~ 7 . 4}$ \\
\hline $\mathbf{5 a}$ & 100 & 85.3 & & 98.4 & 14.8 \\
$\mathbf{5 d}$ & 98.1 & 85.2 & & 92.5 & 8.6 \\
$\mathbf{5 g}$ & 100 & 93.9 & & 94.5 & 34.1 \\
$\mathbf{5 h}$ & 100 & 93.4 & & 94.5 & 52.2 \\
$\mathbf{7 a}$ & 100 & 26.0 & & 96.8 & 0 \\
$\mathbf{7 b}$ & 100 & 17.6 & & 96.9 & 0 \\
$\mathbf{7 c}$ & 100 & 29.4 & & 96.4 & 0 \\
$\mathbf{7 d}$ & 100 & 26.3 & & 95.5 & 0 \\
$\mathbf{7 e}$ & 100 & 23.4 & & 94.5 & 0 \\
$\mathbf{7 f}$ & 100 & 14.4 & & 94.7 & 0 \\
\hline
\end{tabular}

The conversions of the prodrugs to SN-38 in human plasma are summarized in Table 4. All the compounds could be rapidly converted to their active form in plasma. Except for compound $\mathbf{5 h}$, the conversion rate of the prodrugs was more than $35 \%$ after incubation for $1 \mathrm{~h}$ and complete conversion was observed after incubation for $12 \mathrm{~h}$ in plasma. As at $\mathrm{pH}$ 7.4, the conversion rate of the dipeptide derivatives was faster than that of the amino acid derivatives.

Table 4. Conversion of the prodrugs to SN-38 in human plasma.

\begin{tabular}{cccc}
\hline \multirow{2}{*}{ Compound } & \multicolumn{3}{c}{ Conversion (\%) } \\
\cline { 2 - 4 } & $\mathbf{1 ~ h}$ & $\mathbf{3} \mathbf{h}$ & $\mathbf{1 2} \mathbf{~ h}$ \\
\hline $\mathbf{5 a}$ & 38.8 & 74.7 & 100.0 \\
$\mathbf{5 b}$ & 36.5 & 72.5 & 100.0 \\
$\mathbf{5 c}$ & 80.1 & 99.4 & - \\
$\mathbf{5 d}$ & 38.0 & 68.9 & 100.0 \\
$\mathbf{5 e}$ & 77.5 & 99.7 & - \\
$\mathbf{5 f}$ & 74.6 & 99.4 & - \\
$\mathbf{5 g}$ & 36.8 & 64.2 & 98.5 \\
$\mathbf{5 h}$ & 15.3 & 37.4 & 85.4 \\
$\mathbf{7 a}$ & 95.3 & - & - \\
$\mathbf{7 b}$ & 99.6 & - & - \\
$\mathbf{7 c}$ & 99.2 & - & - \\
$\mathbf{7 d}$ & 97.6 & - & - \\
$\mathbf{7 e}$ & 99.6 & - & - \\
$\mathbf{7 f}$ & 98.7 & - & - \\
\hline
\end{tabular}

\subsection{Tumor Growth Inhibitory Activity of 5e in a Human Colon Xenograft Model in Vivo}

The antitumor activity of 5e, compared with CPT-11 and SN-38, was investigated in human colon adenocarcinoma SW1116 xenografts in nude mice. The model animals were divided into four experimental groups, eight animals per group. Tested compouds were each administered by injection in the tumor section once per day for contiguous 6 days. The injection doses of test compound 5e, CPT-11, 
and SN-38 were $60 \mathrm{mg} / \mathrm{kg}$, respectively. Using the vehicle group as the control, we tested the inhibitory activities of these compounds for 6 days and measured the changes in body weight and tumor size every 2 days. The results showed that 5 e inhibited tumor growth by $51 \%$ on day 6 and had about the same in vivo activity compared to CPT-11 (Table 5). SN-38 was less active than 5e and CPT-11, showing an inhibition rate of only $8.6 \%$. No toxic death occurred after drug treatment, and the body weight losses induced by $\mathbf{5 e}, \mathrm{CPT}-11$, and $\mathrm{SN}-38$ at the given dose were similar.

Table 5. Tumor growth inhibitory activity of 5e in a human colon xenograft model in vivo ( $\pm \mathrm{SD}$ ).

\begin{tabular}{|c|c|c|c|c|}
\hline \multirow{2}{*}{ Compound } & Dose & Tumor Weight & Inhibitory Rate & Body Weight Change \\
\hline & $\overline{(\mathrm{mg} / \mathrm{kg})}$ & $(\mathrm{g} / 10 \mathrm{~g})$ & $(\%)$ & (g) \\
\hline Vehicle & & $0.35 \pm 0.12$ & & +0.95 \\
\hline $5 e$ & 60 & $0.17 \pm 0.05 *$ & 51 & -2.72 \\
\hline Irinotecan & 60 & $0.17 \pm 0.04 *$ & 51 & -3.10 \\
\hline SN-38 & 60 & $0.32 \pm 0.12$ & 8.6 & -1.45 \\
\hline
\end{tabular}

\subsection{Discussion}

In order to overcome the drawbacks of the pharmacokinetic properties of irinotecan and find new water soluble camptothecin prodrugs with improved activity and lower side effects, novel prodrugs of SN-38 were designed and synthesized using amino acids or dipeptides as prodrug carriers to replace the 4-piperidinopiperidine moiety of irinotecan. Because of the poor enzymolysis stability of ester bonds directly formed by the $10-\mathrm{OH}$ moiety $\mathrm{f} \mathrm{SN}-38$ when reacting with $\alpha-\mathrm{COOH}$ of amino acids, carbamate linkages were used to conjugate the $10-\mathrm{OH}$ of SN-38 and the $\alpha-\mathrm{NH}_{2}$ of amino acids or dipeptides. Firstly, the water solubility of the designed prodrugs was improved significantly by converting the free carboxyl groups to their carboxylic salts. Next, we tested the chemical stability and plasma stability of these new compounds in different $\mathrm{pH}$ conditions and in human plasma, respectively. The results suggested that the new prodrugs could be stored in acidic solution or in solid state and converted to the active SN-38 in physiological conditions or in human plasma easily, indicating the improved pharmacokinetics property compared with that of Irinotecan. Both in vitro and in vivo biologic evaluation results showed the predominant antitumor activity of these new compounds. Meanwhile, the compounds exhibited only weak inhibitory activity against AChE, reducing the acute cholinergic diarrhea associated with Irinotecan. These results suggest that these compounds could be used as leads for the further design and development of novel anticancer camptothecin derivatives.

\section{Experimental Section}

\subsection{General Information}

Commercially available reagents were purchased from Alfa Aesar (Shanghai, China), and used as supplied without further purification. Reactions were monitored by thin-layer chromatography performed on silica gel $\mathrm{GF}_{254}$ pre-coated plate. Visualization was realized by UV light (365 $\mathrm{nm}$ ). Purification by flash chromatography was realized on silica gel 200-300 mesh. Proton nuclear magnetic resonance $\left({ }^{1} \mathrm{H}-\mathrm{NMR}\right)$ spectra were recorded in DMSO- $d_{6}$ at $400 \mathrm{MHz}$ on a JNM-ECA-400 MHz instrument 
(JEOL Ltd., Tokyo, Japan). Low Resolution Mass Spectroscopy (AB Sciex Pte. Ltd., Framingham, MA, USA) was recorded on an API 150EX LC/MS system, with an electron ionization spray (ESI) technique.

\subsection{Synthesis}

10-OCO-(Gly-OBzl)-SN-38 (4a). H-Gly-OBzl $\cdot \mathrm{HCl}(1.23 \mathrm{~g}, 6.12 \mathrm{mmol})$ was dissolved in a solution of $\mathrm{DCM}(60 \mathrm{~mL})$ and $\mathrm{NaHCO}_{3}$ (saturated aqueous solution $\left.60 \mathrm{~mL}\right)$, and cooled down to $0{ }^{\circ} \mathrm{C}$. After $10 \mathrm{~min}$, BTC ( $668 \mathrm{mg}, 2.25 \mathrm{mmol}$ ) was added and the mixture was stirred for $20 \mathrm{~min}$. The mixture was extracted twice with DCM solution. The combined organic extract were dried over anhydrous sodium sulfate, filtered, and evaporated to give the product as colorless oil without further purification. SN-38 (600 mg, $1.53 \mathrm{mmol}$ ) was dissolved in THF, and $\mathrm{Et}_{3} \mathrm{~N}(618 \mathrm{mg}, 6.12 \mathrm{mmol})$ was added. The mixture was set under $\mathrm{N}_{2}$ atmosphere and stirred at room temperature for $30 \mathrm{~min}$. Thereafter, the isocyanate mentioned above was added and the reaction mixture was stirred at $40{ }^{\circ} \mathrm{C}$ overnight. The mixture was purified by silica gel chromatography with DCM-acetone $=5: 1$ as eluent to give compound 4a (736 $\mathrm{mg}, 82.5 \%$ yield). ${ }^{1} \mathrm{H}-\mathrm{NMR} \delta_{\mathrm{H}}(\mathrm{ppm}): 0.87-0.91(\mathrm{t}, J=7.2 \mathrm{~Hz}, 3 \mathrm{H}), 1.27-1.31(\mathrm{t}, J=7.6 \mathrm{~Hz}, 3 \mathrm{H}), 1.84-1.91(\mathrm{~m}, 2 \mathrm{H})$, $3.15-3.20$ (q, $J=7.6 \mathrm{~Hz}, 2 \mathrm{H}), 3.83-3.84(\mathrm{~d}, J=6.0 \mathrm{~Hz}, 2 \mathrm{H}), 5.30(\mathrm{~s}, 2 \mathrm{H}), 5.43(\mathrm{~s}, 2 \mathrm{H}), 6.55(\mathrm{~s}, 1 \mathrm{H})$, $7.31(\mathrm{~s}, 1 \mathrm{H}), 7.61-7.64(\mathrm{dd}, J=9.6 \mathrm{~Hz}, 2.4 \mathrm{~Hz}, 1 \mathrm{H}), 7.95(\mathrm{~d}, J=2.4 \mathrm{~Hz}, 1 \mathrm{H}), 8.16-8.18(\mathrm{~d}, J=9.6 \mathrm{~Hz}$, $1 \mathrm{H}), 8.28-8.31(\mathrm{t}, J=6.0 \mathrm{~Hz}, 1 \mathrm{H}), 12.68(\mathrm{~s}, 1 \mathrm{H})$. MS (ESI) $m / z: 584.4[\mathrm{M}+\mathrm{H}]^{+}, 606.2[\mathrm{M}+\mathrm{Na}]^{+}$.

10-OCO-(Gly-OH)-SN-38 (5a). Compound 4a (736 mg, $1.26 \mathrm{mmol})$ was dissolved in the solution of THF and ethyl alcohol mixed at a ratio of 7:4. Afterwards, $10 \% \mathrm{Pd} / \mathrm{C}(294 \mathrm{mg})$ was added and the stirred overnight under $\mathrm{H}_{2}$ atmosphere. The reaction mixture was filtered, the filtrate was evaporated immediately and chromatographed on silica gel (DCM-acetone $=2: 1$ with $1 \%$ TFA) to give compound 5a as a yellow powder (446 mg, 71.7\% yield). ${ }^{1} \mathrm{H}-\mathrm{NMR} \delta_{\mathrm{H}}(\mathrm{ppm}): 0.87-0.91$ (t, $\left.J=7.2 \mathrm{~Hz}, 3 \mathrm{H}\right), 1.27-1.31$ $(\mathrm{t}, J=7.6 \mathrm{~Hz}, 3 \mathrm{H}), 1.84-1.91(\mathrm{~m}, 2 \mathrm{H}), 3.15-3.20(\mathrm{q}, J=7.6 \mathrm{~Hz}, 2 \mathrm{H}), 3.83-3.84(\mathrm{~d}, J=6.0 \mathrm{~Hz}, 2 \mathrm{H})$, $5.30(\mathrm{~s}, 2 \mathrm{H}), 5.43(\mathrm{~s}, 2 \mathrm{H}), 6.55(\mathrm{~s}, 1 \mathrm{H}), 7.31(\mathrm{~s}, 1 \mathrm{H}), 7.61-7.64(\mathrm{dd}, J=9.6 \mathrm{~Hz}, 2.4 \mathrm{~Hz}, 1 \mathrm{H}), 7.95(\mathrm{~d}$, $J=2.4 \mathrm{~Hz}, 1 \mathrm{H}), 8.16-8.18(\mathrm{~d}, J=9.6 \mathrm{~Hz}, 1 \mathrm{H}), 8.28-8.31(\mathrm{t}, J=6.0 \mathrm{~Hz}, 1 \mathrm{H}), 12.68(\mathrm{~s}, 1 \mathrm{H}) . \mathrm{MS}(\mathrm{ESI}) \mathrm{m} / z$ : $494.3[\mathrm{M}+\mathrm{H}]^{+}, 516.3[\mathrm{M}+\mathrm{Na}]^{+}$.

10-OCO-(Ala-OH)-SN-38 (5b). Compound 5b was synthesized by a similar procedure as 5a. $\mathrm{H}$-Ala-OBzl•TosOH (2.26 g, $6.43 \mathrm{mmol})$ and SN-38 (600 mg, $1.53 \mathrm{mmol}$ ) were employed to produced 4b (yellow powder, $862 \mathrm{mg}, 94 \%$ ), which was then hydrogenated to $5 \mathbf{b}$ with $\mathrm{Pd} / \mathrm{C}$, producing a yellow powder (625 mg, 85.4\%). $\delta_{\mathrm{H}}(\mathrm{ppm}): 0.87-0.90(\mathrm{t}, J=7.2 \mathrm{~Hz}, 3 \mathrm{H}), 1.27-1.31(\mathrm{t}, J=7.6 \mathrm{~Hz}, 3 \mathrm{H})$, $1.38-1.41(\mathrm{~d}, J=7.6 \mathrm{~Hz}, 3 \mathrm{H}), 1.82-1.91(\mathrm{~m}, 2 \mathrm{H}), 3.15-3.20$ (q, $J=7.6 \mathrm{~Hz}, 2 \mathrm{H}), 4.12-4.15(\mathrm{~m}, 1 \mathrm{H})$, $5.31(\mathrm{~s}, 2 \mathrm{H}), 5.44(\mathrm{~s}, 2 \mathrm{H}), 6.55(\mathrm{~s}, 1 \mathrm{H}), 7.31(\mathrm{~s}, 1 \mathrm{H}), 7.58-7.63(\mathrm{dd}, J=9.2 \mathrm{~Hz}, 2.4 \mathrm{~Hz}, 1 \mathrm{H}), 7.94-7.95$ $(\mathrm{d}, J=2.4 \mathrm{~Hz}, 1 \mathrm{H}), 8.14-8.18(\mathrm{~d}, J=9.2 \mathrm{~Hz}, 1 \mathrm{H}), 8.35-8.37$ (t, $J=7.6 \mathrm{~Hz}, 1 \mathrm{H}), 12.79$ (s, $1 \mathrm{H}) . \mathrm{MS}$ (ESI) $m / z: 508.4[\mathrm{M}+\mathrm{H}]^{+}$.

10-OCO-(Val-OH)-SN-38 (5c). Compound 5c was synthesized by a similar procedure as 5a. $\mathrm{H}-\mathrm{Val}-\mathrm{OBz} \cdot \mathrm{TosOH}(1.94 \mathrm{~g}, 5.12 \mathrm{mmol})$ and SN-38 (500 mg, $1.28 \mathrm{mmol})$ were employed to produce $\mathbf{4 c}$ as a yellow powder $(797 \mathrm{mg}, 100 \%)$, then hydrogenated to $\mathbf{5 c}$ with $\mathrm{Pd} / \mathrm{C}$, producing a yellow powder (271 mg, 39.7\%). ${ }^{1} \mathrm{H}-\mathrm{NMR} \delta_{\mathrm{H}}$ (ppm): 0.87-0.90 (t, $\left.J=7.2 \mathrm{~Hz}, 3 \mathrm{H}\right), 0.98-1.01$ (q, $J=3.2 \mathrm{~Hz}, 6 \mathrm{H}$ ), $1.28-1.32(\mathrm{t}, J=7.6 \mathrm{~Hz}, 3 \mathrm{H}), 1.82-1.93(\mathrm{~m}, 2 \mathrm{H}), 2.14-2.19(\mathrm{~m}, 1 \mathrm{H}), 3.16-3.22(\mathrm{q}, J=7.6 \mathrm{~Hz}, 2 \mathrm{H})$, 
3.96-4.00 (dd, $J=5.6 \mathrm{~Hz}, 8.4 \mathrm{~Hz}, 1 \mathrm{H}), 5.32(\mathrm{~s}, 2 \mathrm{H}), 5.43(\mathrm{~s}, 2 \mathrm{H}), 6.51(\mathrm{~s}, 1 \mathrm{H}), 7.32(\mathrm{~s}, 1 \mathrm{H}), 7.61-7.63$ $(\mathrm{dd}, J=2.4 \mathrm{~Hz}, 9.2 \mathrm{~Hz}, 1 \mathrm{H}), 7.95(\mathrm{~d}, J=2.4 \mathrm{~Hz}, 1 \mathrm{H}), 8.17-8.19(\mathrm{~d}, J=9.2 \mathrm{~Hz}, 1 \mathrm{H}), 8.22-8.44$ (d, $J=8.4 \mathrm{~Hz}, 1 \mathrm{H}), 12.72(\mathrm{~s}, 1 \mathrm{H})$. MS (ESI) $m / z: 536.6[\mathrm{M}+\mathrm{H}]^{+}$.

10-OCO-(Glu-OH)-SN-38 (5d). Compound 5d was synthesized by a similar procedure as 5a. $\mathrm{H}-\mathrm{Glu}(\mathrm{OBzl})-\mathrm{OBzl} \bullet \mathrm{TosOH}(2.55 \mathrm{~g}, 5.10 \mathrm{mmol})$ and SN-38 (500 mg, $1.28 \mathrm{mmol})$ were employed to produce 4d (yellow powder, $1.03 \mathrm{~g}, 100 \%$ ), which was then hydrogenated to $5 \mathbf{d}$ with $\mathrm{Pd} / \mathrm{C}$, producing a yellow powder (368 mg, 51.0\%). ${ }^{1} \mathrm{H}-\mathrm{NMR} \delta_{\mathrm{H}}(\mathrm{ppm}): \delta=0.87-0.90(\mathrm{t}, J=7.2 \mathrm{~Hz}, 3 \mathrm{H}), 1.28-1.31(\mathrm{t}$, $J=7.6 \mathrm{~Hz}, 3 \mathrm{H}), 1.86-1.91(\mathrm{~m}, 2 \mathrm{H}), 2.09-2.12(\mathrm{~m}, 2 \mathrm{H}), 2.48-2.51(\mathrm{~m}, 2 \mathrm{H}), 3.18-3.20(\mathrm{q}, J=6.8 \mathrm{~Hz}$, $2 \mathrm{H}), 4.12-4.13(\mathrm{~m}, 1 \mathrm{H}), 5.32(\mathrm{~s}, 2 \mathrm{H}), 5.43(\mathrm{~s}, 2 \mathrm{H}), 6.54(\mathrm{~s}, 1 \mathrm{H}), 7.32(\mathrm{~s}, 1 \mathrm{H}), 7.62-7.64(\mathrm{~d}, J=8.4 \mathrm{~Hz}$, 1H), $7.96(\mathrm{~s}, 1 \mathrm{H}), 8.15-8.17(\mathrm{~d}, J=8.0 \mathrm{~Hz}, 1 \mathrm{H}), 8.32-8.34(\mathrm{~d}, J=7.6 \mathrm{~Hz}, 1 \mathrm{H}), 12.58(\mathrm{~s}, 2 \mathrm{H})$. MS (ESI) $m / z: 566.4[\mathrm{M}+\mathrm{H}]^{+}, 588.4[\mathrm{M}+\mathrm{Na}]^{+}$.

10-OCO-(Leu-OH)-SN-38 (5e). Compound 5e was synthesized by a similar procedure as 5a. $\mathrm{H}-\mathrm{Leu}-\mathrm{OBzl} \cdot \mathrm{Tos} \mathrm{OH}(2.01 \mathrm{~g}, 5.10 \mathrm{mmol})$ and SN-38 (500 mg, $1.28 \mathrm{mmol}$ ) were employed to produce 4e (yellow powder, $600 \mathrm{mg}, 73.6 \%$ ), which was then hydrogenated to $5 \mathbf{e}$ with $\mathrm{Pd} / \mathrm{C}$, producing a yellow powder (51 mg, 19.9\%). ${ }^{1} \mathrm{H}-\mathrm{NMR} \delta \mathrm{H}(\mathrm{ppm}): 0.94-1.02(\mathrm{~m}, 9 \mathrm{H}), 1.33-1.36(\mathrm{t}, J=7.6 \mathrm{~Hz}, 3 \mathrm{H}), 1.63-1.66$ (m, 1H), 1.69-1.73 (m, 2H), 1.89-1.96 (m, 2H), 3.23-3.27 (q, J=7.6 Hz, 2H), 4.12-4.14 (m, 1H), 5.38 (s, 2H), $5.50(\mathrm{~s}, 2 \mathrm{H}), 6.61(\mathrm{~s}, 1 \mathrm{H}), 7.37(\mathrm{~s}, 1 \mathrm{H}), 7.65-7.68(\mathrm{dd}, J=9.2 \mathrm{~Hz}, 2.8 \mathrm{~Hz}, 1 \mathrm{H}), 8.00-8.01$ (d, $J=2.4 \mathrm{~Hz}, 1 \mathrm{H}), 8.22-8.25(\mathrm{~d}, J=9.2 \mathrm{~Hz}, 1 \mathrm{H}), 8.38-8.40$ (d, $J=8 \mathrm{~Hz}, 1 \mathrm{H}), 12.81(\mathrm{~s}, 1 \mathrm{H})$. MS (ESI) $m / z: 550.4[\mathrm{M}+\mathrm{H}]^{+}, 572.4[\mathrm{M}+\mathrm{Na}]^{+}$.

10-OCO-(Ile-OH)-SN-38 (5f). Compound $\mathbf{5 f}$ was synthesized by a similar procedure as 5a. $\mathrm{H}-\mathrm{Ile}-\mathrm{OBz} \cdot \mathrm{TosOH}$ (2.01 g, $5.10 \mathrm{mmol})$ and SN-38 (500 $\mathrm{mg}, 1.28 \mathrm{mmol}$ ) were employed to produce $\mathbf{4 f}$ (yellow powder, $757 \mathrm{mg}, 92.8 \%$ ), which was then hydrogenated to $\mathbf{5 f}$ with $\mathrm{Pd} / \mathrm{C}$, producing a yellow powder (40 mg, 15.0\%). ${ }^{1} \mathrm{H}-\mathrm{NMR} \delta_{\mathrm{H}}(\mathrm{ppm})$ : 0.86-0.97 (m, $\left.9 \mathrm{H}\right), 1.27-1.33(\mathrm{~m}, 4 \mathrm{H}), 1.47-1.51$ (m, $1 \mathrm{H}), 1.83-1.93(\mathrm{~m}, 3 \mathrm{H}), 3.16-3.22$ (q, $J=7.6 \mathrm{~Hz}, 2 \mathrm{H}), 4.00-4.02(\mathrm{~m}, 1 \mathrm{H}), 5.32(\mathrm{~s}, 2 \mathrm{H}), 5.44(\mathrm{~s}, 2 \mathrm{H})$, $6.55(\mathrm{~s}, 1 \mathrm{H}), 7.32(\mathrm{~s}, 1 \mathrm{H}), 7.61-7.64(\mathrm{dd}, J=8.8 \mathrm{~Hz}, 2.4 \mathrm{~Hz}, 1 \mathrm{H}), 7.95-7.96(\mathrm{~d}, J=2.4 \mathrm{~Hz}, 1 \mathrm{H})$, $8.17-8.19(\mathrm{~d}, J=8.8 \mathrm{~Hz}, 1 \mathrm{H}), 8.27-8.29(\mathrm{~d}, J=8.4 \mathrm{~Hz}, 1 \mathrm{H}), 12.80(\mathrm{~s}, 1 \mathrm{H}) . \mathrm{MS}(\mathrm{ESI}) \mathrm{m} / z: 550.3[\mathrm{M}+\mathrm{H}]^{+}$, $572.4[\mathrm{M}+\mathrm{Na}]^{+}$.

10-OCO-(L-Asp-OH)-SN-38 (5g). Compound $\mathbf{5 g}$ was synthesized by a similar procedure as 5a. $\mathrm{H}-\mathrm{L}-\mathrm{Asp}(\mathrm{OBzl})-\mathrm{OBzl} \bullet \mathrm{TosOH}(2.48 \mathrm{~g}, 5.10 \mathrm{mmol})$ and $\mathrm{SN}-38(500 \mathrm{mg}, 1.28 \mathrm{mmol})$ were employed to produce $\mathbf{4 g}$ (yellow powder, $920 \mathrm{mg}, 98.6 \%$ ), which was then hydrogenated to $\mathbf{5 g}$ with $\mathrm{Pd} / \mathrm{C}$, producing a yellow powder $(521 \mathrm{mg}, 75.0 \%) .{ }^{1} \mathrm{H}-\mathrm{NMR} \delta_{\mathrm{H}}(\mathrm{ppm}): 0.86-0.90(\mathrm{t}, J=7.2 \mathrm{~Hz}, 3 \mathrm{H}), 1.27-1.31(\mathrm{t}$, $J=7.6 \mathrm{~Hz}, 3 \mathrm{H}), 1.81-1.92(\mathrm{~m}, 2 \mathrm{H}), 2.65-2.72(\mathrm{q}, J=7.6 \mathrm{~Hz}, 16.8 \mathrm{~Hz}, 1 \mathrm{H}), 2.80-2.85(\mathrm{q}, J=5.8 \mathrm{~Hz}$, $16.8 \mathrm{~Hz}, 1 \mathrm{H}), 3.16-3.22(\mathrm{q}, J=7.6 \mathrm{~Hz}, 2 \mathrm{H}), 4.40-4.44(\mathrm{~m}, 1 \mathrm{H}), 5.34(\mathrm{~s}, 2 \mathrm{H}), 5.44(\mathrm{~s}, 2 \mathrm{H}), 6.56(\mathrm{~s}, 1 \mathrm{H})$, $7.32(\mathrm{~s}, 1 \mathrm{H}), 7.36-7.40(\mathrm{~m}, 10 \mathrm{H}), 7.61-7.63(\mathrm{dd}, J=9.2 \mathrm{~Hz}, 2.4 \mathrm{~Hz}, 1 \mathrm{H}), 7.96-7.97(\mathrm{~d}, J=2.4 \mathrm{~Hz}, 1 \mathrm{H})$, 8.18-8.20 (d, $J=9.2 \mathrm{~Hz}, 1 \mathrm{H}), 8.34-8.36(\mathrm{dd}, J=8.4 \mathrm{~Hz}, 1 \mathrm{H}), 12.89$ (s, 2H). MS (ESI) $m / z: 552.3$ $[\mathrm{M}+\mathrm{H}]^{+}, 574.5[\mathrm{M}+\mathrm{Na}]^{+}$. 
10-OCO-(D-Asp-OH)-SN-38 (5h). Compound $\mathbf{5 h}$ was synthesized by a similar procedure as $\mathbf{5 a}$. H-D-Asp(OBzl)-OBzl-TosOH (2.48 g, $5.10 \mathrm{mmol})$ and SN-38 (500 mg, $1.28 \mathrm{mmol})$ were employed to produce $4 \mathbf{h}$ (yellow powder, $810 \mathrm{mg}, 86.8 \%$ ), which was then hydrogenated to $\mathbf{5 h}$ with $\mathrm{Pd} / \mathrm{C}$, producing a yellow powder $(422 \mathrm{mg}, 70.0 \%)$. ${ }^{1} \mathrm{H}-\mathrm{NMR} \delta_{\mathrm{H}}(\mathrm{ppm}): 0.86-0.89(\mathrm{t}, J=7.2 \mathrm{~Hz}, 3 \mathrm{H}), 1.27-1.30(\mathrm{t}$, $J=7.6 \mathrm{~Hz}, 3 \mathrm{H}), 1.84-1.90(\mathrm{~m}, 2 \mathrm{H}), 2.71-2.73(\mathrm{q}, 1 \mathrm{H}), 2.80-2.82(\mathrm{q}, 1 \mathrm{H}), 3.16-3.18(\mathrm{q}, J=7.6 \mathrm{~Hz}$, $2 \mathrm{H}), 4.44-4.47(\mathrm{~m}, 1 \mathrm{H}), 5.31(\mathrm{~s}, 2 \mathrm{H}), 5.43(\mathrm{~s}, 2 \mathrm{H}), 6.54(\mathrm{~s}, 1 \mathrm{H}), 7.31(\mathrm{~s}, 1 \mathrm{H}), 7.59-7.62(\mathrm{dd}, J=9.2 \mathrm{~Hz}$, $2.4 \mathrm{~Hz}, 1 \mathrm{H}), 7.94-7.95(\mathrm{~d}, J=2.4 \mathrm{~Hz}, 1 \mathrm{H}), 8.16-8.18(\mathrm{~d}, J=9.2 \mathrm{~Hz}, 1 \mathrm{H}), 8.34-8.36$ (d, $J=8.4 \mathrm{~Hz}$, $1 \mathrm{H}), 12.80-12.83(\mathrm{~s}, 2 \mathrm{H})$. MS (ESI) $m / z: 552.3[\mathrm{M}+\mathrm{H}]^{+}, 574.5[\mathrm{M}+\mathrm{Na}]^{+}$.

10-OCO-(D-Asp-Gly-OBzl)-SN-38 (6a). Under the ice-bath conditions, 5a (446 mg, $0.90 \mathrm{mmol}$ ) was dissolved in THF (100 mL), followed by addition of HOBt (224 mg, $1.80 \mathrm{mmol})$ and DIEA (582 mg, $4.50 \mathrm{mmol}$ ) in sequence. The mixture was placed under a $\mathrm{N}_{2}$ atmosphere and stirred for $20 \mathrm{~min}$, and then H-D-Asp (OBzl)-OBzl•TosOH (485.6 mg, $0.99 \mathrm{mmol}$ ), and DCC (206 mg, $0.99 \mathrm{mmol}$ ) were added. Thereafter, the reaction mixture was stirred at room temperature for $24 \mathrm{~h}$. The mixture was purified by silica gel chromatography with DCM-acetone $=3: 1$ as eluent to give compound $\mathbf{6 a}$ ( $241 \mathrm{mg}, 34 \%$ ). ${ }^{1} \mathrm{H}-\mathrm{NMR} \delta_{\mathrm{H}}(\mathrm{ppm}): 0.87-0.90(\mathrm{t}, J=7.2 \mathrm{~Hz}, 3 \mathrm{H}), 1.28-1.32(\mathrm{t}, J=7.6 \mathrm{~Hz}, 3 \mathrm{H}), 1.86-1.89(\mathrm{~m}, 2 \mathrm{H})$, 2.88-2.89 (q, 1H), 2.95-2.96 (q, 1H), 3.14-3.15 (q, $J=7.6 \mathrm{~Hz}, 2 \mathrm{H}), 3.84-3.89$ (d, $J=5.6 \mathrm{~Hz}, 2 \mathrm{H})$, $4.84-4.86(\mathrm{q}, 1 \mathrm{H}), 4.55-4.59(\mathrm{q}, 1 \mathrm{H}), 5.13(\mathrm{~s}, 2 \mathrm{H}), 5.21(\mathrm{~s}, 2 \mathrm{H}), 5.27(\mathrm{~s}, 2 \mathrm{H}), 5.45(\mathrm{~s}, 2 \mathrm{H}), 6.57(\mathrm{~s}, 1 \mathrm{H})$, $7.35(\mathrm{~s}, 11 \mathrm{H}), 7.63-7.65(\mathrm{dd}, J=8.8 \mathrm{~Hz}, 2.0 \mathrm{~Hz}, 1 \mathrm{H}), 7.94(\mathrm{~d}, J=2.0 \mathrm{~Hz}, 1 \mathrm{H}), 8.14-8.16(\mathrm{~d}, J=8.4 \mathrm{~Hz}$, $1 \mathrm{H}), 8.25(\mathrm{~s}, 1 \mathrm{H}), 8.66-8.68(\mathrm{~d}, J=8.0 \mathrm{~Hz}, 1 \mathrm{H})$. MS (ESI) $m / z: 789.7[\mathrm{M}+\mathrm{H}]^{+}, 811.7[\mathrm{M}+\mathrm{Na}]^{+}$.

10-OCO-(D-Asp-Gly-OH)-SN-38 (7a). Compound 6a (241 $\mathrm{mg}, 0.31 \mathrm{mmol})$ was dissolved in a solution of THF and ethyl alcohol mixed at the ratio of 7:4. Afterwards, $10 \% \mathrm{Pd} / \mathrm{C}(96.4 \mathrm{mg})$ was added and the mixture was stirred overnight under a $\mathrm{H}_{2}$ atmosphere. The reaction mixture was filtered, the filtrate was evaporated immediately and was chromatographed on silica gel (DCM-acetone $=2: 1$ with $1 \%$ TFA) to give compound $7 \mathbf{a}\left(95 \mathrm{mg}, 51 \%\right.$ yield), as a yellow powder. ${ }^{1} \mathrm{H}-\mathrm{NMR} \delta_{\mathrm{H}}(\mathrm{ppm}): 0.87-0.90(\mathrm{t}, J=7.2 \mathrm{~Hz}$, $3 \mathrm{H}), 1.28-1.32(\mathrm{t}, J=7.6 \mathrm{~Hz}, 3 \mathrm{H}), 1.86-1.89(\mathrm{~m}, 2 \mathrm{H}), 2.64-2.66(\mathrm{q}, 1 \mathrm{H}), 2.70-2.73(\mathrm{q}, 1 \mathrm{H}), 3.18-3.20$ $(\mathrm{q}, J=7.6 \mathrm{~Hz}, 2 \mathrm{H}), 3.78-3.80(\mathrm{~d}, J=5.6 \mathrm{~Hz}, 2 \mathrm{H}), 4.59-4.62(\mathrm{q}, 1 \mathrm{H}), 5.33(\mathrm{~s}, 2 \mathrm{H}), 5.44(\mathrm{~s}, 2 \mathrm{H}), 6.52(\mathrm{~s}$, $1 \mathrm{H}), 7.33(\mathrm{~s}, 1 \mathrm{H}), 7.64-7.66(\mathrm{dd}, J=8.8 \mathrm{~Hz}, 2.0 \mathrm{~Hz}, 1 \mathrm{H}), 7.96(\mathrm{~d}, J=2.0 \mathrm{~Hz}, 1 \mathrm{H}), 8.13(\mathrm{~s}, 1 \mathrm{H})$, $8.17-8.19(\mathrm{~d}, J=8.8 \mathrm{~Hz}, 1 \mathrm{H}), 8.32-8.34(\mathrm{~d}, J=8.0 \mathrm{~Hz}, 1 \mathrm{H}), 12.64(\mathrm{~s}, 2 \mathrm{H})$. MS (ESI) $m / z: 609.4[\mathrm{M}+\mathrm{H}]^{+}$, $631.4[\mathrm{M}+\mathrm{Na}]^{+}$.

10-OCO-(L-Asp-Gly-OH)-SN-38 (7b). Compound $7 \mathbf{b}$ was synthesized by a similar procedure as $7 \mathbf{a}$. $\mathrm{H}-\mathrm{L}-\mathrm{Asp}(\mathrm{OBzl})-\mathrm{OBzl} \cdot \mathrm{TosOH}(336 \mathrm{mg}, 0.69 \mathrm{mmol}$ ) and compound 4a $(311 \mathrm{mg}, 0.63 \mathrm{mmol}$ ) were employed to produce $\mathbf{6 b}$ (yellow powder, $240 \mathrm{mg}, 48.3 \%$ ), which was then hydrogenated to $7 \mathbf{b}$ with $\mathrm{Pd} / \mathrm{C}$, producing a yellow powder $(115 \mathrm{mg}, 72.7 \%) .{ }^{1} \mathrm{H}-\mathrm{NMR} \delta_{\mathrm{H}}(\mathrm{ppm}): 0.86-0.90(\mathrm{t}, J=7.2 \mathrm{~Hz}, 3 \mathrm{H})$, $1.27-1.31(\mathrm{t}, J=7.6 \mathrm{~Hz}, 3 \mathrm{H}), 1.81-1.92(\mathrm{~m}, 2 \mathrm{H}), 2.60-2.65(\mathrm{q}, 1 \mathrm{H}), 2.69-2.73(\mathrm{q}, 1 \mathrm{H}), 3.18-3.20$ (q, $J=7.6 \mathrm{~Hz}, 2 \mathrm{H}), 3.78-3.79(\mathrm{~d}, J=6.0 \mathrm{~Hz}, 2 \mathrm{H}), 4.55-4.60(\mathrm{q}, 1 \mathrm{H}), 5.34$ (s, 2H), 5.44 (s, 2H), 6.56 (s, $1 \mathrm{H}), 7.32(\mathrm{~s}, 1 \mathrm{H}), 7.64-7.67(\mathrm{dd}, J=9.2 \mathrm{~Hz}, 2.4 \mathrm{~Hz}, 1 \mathrm{H}), 7.96-7.97(\mathrm{~d}, J=2.4 \mathrm{~Hz}, 1 \mathrm{H}), 8.17-8.20$ (d, $J=9.2 \mathrm{~Hz}, 1 \mathrm{H}), 8.21-8.24(\mathrm{t}, J=6.0 \mathrm{~Hz}, 1 \mathrm{H}), 8.33-8.35(\mathrm{~d}, J=7.6 \mathrm{~Hz}, 1 \mathrm{H}), 12.79(\mathrm{~s}, 2 \mathrm{H})$. MS (ESI) $m / z: 609.3[\mathrm{M}+\mathrm{H}]^{+}, 631.4[\mathrm{M}+\mathrm{Na}]^{+}$. 
10-OCO-(Glu-Gly-OH)-SN-38 (7c). Compound 7c was synthesized by a similar procedure as $7 \mathbf{a}$. $\mathrm{H}-\mathrm{L}-\mathrm{Glu}(\mathrm{OBzl})-\mathrm{OBzl} \cdot \mathrm{HCL}(382 \mathrm{mg}, 1.05 \mathrm{mmol})$ and compound 4a (471 $\mathrm{mg}, 0.96 \mathrm{mmol}$ ) were employed to produce $\mathbf{6 c}$ (yellow powder, $440 \mathrm{mg}, 57.5 \%$ ), which was then hydrogenated to 7c with $\mathrm{Pd} / \mathrm{C}$, producing a yellow powder $(230 \mathrm{mg}, 72.8 \%) .{ }^{1} \mathrm{H}-\mathrm{NMR} \delta \mathrm{H}(\mathrm{ppm}): 0.86-0.90(\mathrm{t}, J=7.2 \mathrm{~Hz}, 3 \mathrm{H})$, $1.27-1.31(\mathrm{t}, J=7.6 \mathrm{~Hz}, 3 \mathrm{H}), 1.83-2.00(\mathrm{~m}, 4 \mathrm{H}), 2.29-2.31(\mathrm{~m}, 2 \mathrm{H}), 3.17-3.19(\mathrm{q}, J=7.6 \mathrm{~Hz}, 2 \mathrm{H})$, $3.79-3.82(\mathrm{t}, J=5.6 \mathrm{~Hz}, 2 \mathrm{H}), 4.29-4.30(\mathrm{~m}, 1 \mathrm{H}), 5.32(\mathrm{~s}, 2 \mathrm{H}), 5.44(\mathrm{~s}, 2 \mathrm{H}), 6.56(\mathrm{~s}, 1 \mathrm{H}), 7.32(\mathrm{~s}, 1 \mathrm{H})$, 7.64-7.66 (dd, $J=9.2 \mathrm{~Hz}, 2.4 \mathrm{~Hz}, 1 \mathrm{H}), 7.96(\mathrm{~d}, J=2.4 \mathrm{~Hz}, 1 \mathrm{H}), 8.14-8.19$ (m, 2H), 8.31 (d, 1H), 12.55 (s, 2H). MS (ESI) $m / z: 623.4[\mathrm{M}+\mathrm{H}]^{+}, 645.4[\mathrm{M}+\mathrm{Na}]^{+}$.

10-OCO-(D-Asp-Ala-OH)-SN-38 (7d). Compound 7d was synthesized by a similar procedure as $7 \mathbf{a}$. H-D-Asp(OBzl)-OBzl•TosOH (652 mg, $1.34 \mathrm{mmol})$ and compound $\mathbf{4 b}(619 \mathrm{mg}, 1.22 \mathrm{mmol})$ were employed to produce $\mathbf{6 d}$ (yellow powder, $700 \mathrm{mg}, 71.3 \%$ ), which was then hydrogenated to $7 \mathbf{d}$ with $\mathrm{Pd} / \mathrm{C}$, producing a yellow powder $(90 \mathrm{mg}, 40.0 \%) .{ }^{1} \mathrm{H}-\mathrm{NMR} \delta \mathrm{H}(\mathrm{ppm}): 0.87-0.91(\mathrm{t}, J=7.2 \mathrm{~Hz}, 3 \mathrm{H})$, $1.22-1.34(\mathrm{~m}, 6 \mathrm{H}), 1.86(\mathrm{~m}, 2 \mathrm{H}), 3.19-3.26(\mathrm{~m}, 2 \mathrm{H}), 3.59(\mathrm{~m}, 2 \mathrm{H}), 4.19(\mathrm{~m}, 1 \mathrm{H}), 4.52-4.59(\mathrm{q}, 1 \mathrm{H})$, $5.33(\mathrm{~s}, 2 \mathrm{H}), 5.43(\mathrm{~s}, 2 \mathrm{H}), 6.55(\mathrm{~s}, 1 \mathrm{H}), 7.31(\mathrm{~s}, 1 \mathrm{H}), 7.63(\mathrm{dd}, J=9.2 \mathrm{~Hz}, 2.8 \mathrm{~Hz}, 1 \mathrm{H}), 7.95(\mathrm{~d}, J=2.8 \mathrm{~Hz}$, $1 \mathrm{H}), 8.16-8.31(\mathrm{~m}, 3 \mathrm{H}), 12.71(\mathrm{~s}, 2 \mathrm{H})$. MS (ESI) $\mathrm{m} / \mathrm{z}: 623.4[\mathrm{M}+\mathrm{H}]^{+}, 645.3[\mathrm{M}+\mathrm{Na}]^{+}$.

10-OCO-(L-Asp-Ala-OH)-SN-38 (7e). Compound 7e was synthesized by a similar procedure as $7 \mathbf{a}$. H-L-Asp(OBzl)-OBzl•TosOH (392 mg, $0.77 \mathrm{mmol}$ ) and compound $4 \mathbf{b}$ (392 mg, $0.77 \mathrm{mmol}$ ) were employed to produce 6e (yellow powder, $400 \mathrm{mg}, 64.6 \%$ ), which was then hydrogenated to 7e with $\mathrm{Pd} / \mathrm{C}$, producing a yellow powder (124 mg, 42.6\%). ${ }^{1} \mathrm{H}-\mathrm{NMR} \delta \mathrm{H}(\mathrm{ppm}): 0.87-0.91(\mathrm{t}, J=7.2 \mathrm{~Hz}, 3 \mathrm{H})$, $1.29-1.31(\mathrm{t}, J=7.6 \mathrm{~Hz}, 3 \mathrm{H}), 1.33-1.35(\mathrm{~d}, J=7.6 \mathrm{~Hz}, 3 \mathrm{H}), 1.82-1.93(\mathrm{~m}, 2 \mathrm{H}), 2.62-2.67$ (q, $1 \mathrm{H})$, $2.70-2.76(\mathrm{q}, 1 \mathrm{H}), 3.15-3.20(\mathrm{q}, J=7.6 \mathrm{~Hz}, 2 \mathrm{H}), 4.19-4.24(\mathrm{~m}, 1 \mathrm{H}), 4.58-4.60(\mathrm{~m}, 1 \mathrm{H}), 5.31(\mathrm{~s}, 2 \mathrm{H})$, $5.44(\mathrm{~s}, 2 \mathrm{H}), 6.52(\mathrm{~s}, 1 \mathrm{H}), 7.32(\mathrm{~s}, 1 \mathrm{H}), 7.62-7.65(\mathrm{dd}, J=9.2 \mathrm{~Hz}, 2.4 \mathrm{~Hz}, 1 \mathrm{H}), 7.94-7.95(\mathrm{~d}, J=2.4 \mathrm{~Hz}$, $1 \mathrm{H}), 8.14-8.20(\mathrm{~m}, 2 \mathrm{H}), 8.27-8.29(\mathrm{~d}, J=8.0 \mathrm{~Hz}, 1 \mathrm{H}), 12.64(\mathrm{~s}, 2 \mathrm{H}) . \mathrm{MS}(\mathrm{ESI}) \mathrm{m} / z: 623.4[\mathrm{M}+\mathrm{H}]^{+}$, $645.5[\mathrm{M}+\mathrm{Na}]^{+}$.

10-OCO-(Glu-Ala-OH)-SN-38 (7f). Compound $7 \mathbf{f}$ was synthesized by a similar procedure as $7 \mathbf{a}$. $\mathrm{H}-\mathrm{L}-\mathrm{Glu}(\mathrm{OBzl})-\mathrm{OBzl} \cdot \mathrm{HCl}$ (493 $\mathrm{mg}, 1.36 \mathrm{mmol})$ and compound $\mathbf{4 b}(625 \mathrm{mg}, 1.23 \mathrm{mmol})$ were employed to produce $6 \mathbf{f}$ (yellow powder, $690 \mathrm{mg}, 69.0 \%$ ), which was then hydrogenated to $7 \mathbf{f}$ with $\mathrm{Pd} / \mathrm{C}$, producing a yellow powder $(260 \mathrm{mg}, 50.3 \%) .{ }^{1} \mathrm{H}-\mathrm{NMR} \delta_{\mathrm{H}}(\mathrm{ppm}): 0.87-0.91(\mathrm{t}, J=7.2 \mathrm{~Hz}, 3 \mathrm{H}), 1.29-1.31$ (t, $J=7.6 \mathrm{~Hz}, 3 \mathrm{H}), 1.33-1.35(\mathrm{~d}, J=7.2 \mathrm{~Hz}, 3 \mathrm{H}), 1.82-1.91(\mathrm{~m}, 2 \mathrm{H}), 2.01-2.03(\mathrm{~m}, 2 \mathrm{H}), 2.29-2.34(\mathrm{~m}$, 2H), 3.15-3.20 (q, $J=7.6 \mathrm{~Hz}, 2 \mathrm{H}), 4.19-4.22(\mathrm{t}, J=7.2 \mathrm{~Hz}, 1 \mathrm{H}), 4.27-4.29(\mathrm{~m}, 1 \mathrm{H}), 5.31(\mathrm{~s}, 2 \mathrm{H}), 5.44$ $(\mathrm{s}, 2 \mathrm{H}), 6.51(\mathrm{~s}, 1 \mathrm{H}), 7.32(\mathrm{~s}, 1 \mathrm{H}), 7.62-7.65(\mathrm{dd}, J=9.2 \mathrm{~Hz}, 2.4 \mathrm{~Hz}, 1 \mathrm{H}), 7.94(\mathrm{~d}, J=2.4 \mathrm{~Hz}, 1 \mathrm{H})$, 8.14-8.18 (m, 2H), 8.24-8.26 (d, $J=8.0 \mathrm{~Hz}, 1 \mathrm{H}), 12.42(\mathrm{~s}, 2 \mathrm{H}) . \mathrm{MS}(\mathrm{ESI}) \mathrm{m} / z: 637.3[\mathrm{M}+\mathrm{H}]^{+}$, $659.4[\mathrm{M}+\mathrm{Na}]^{+}$.

\subsection{Cytotoxicity Study}

The in vitro antitumor activity was evaluated on two human cancer cell lines with the MTT method. SGC-7901 is a human gastric adenocarcinoma cancer cell line and HeLa is a human cervical carcinoma cell line. Cells were provided by the Jilin Province Tumor Institute. Cells were maintained in IMDM medium supplemented with $10 \%$ fetal calf serum, $2 \mathrm{mM}$ glutamine, $100 \mathrm{U} / \mathrm{mL}$ penicillin, and $100 \mu \mathrm{g} / \mathrm{mL}$ 
streptomycin, at $37{ }^{\circ} \mathrm{C}$ in a humidified atmosphere containing $5 \% \mathrm{CO}_{2}$. The human cancer lines SGC-7901 and HELA at a concentration of $2.5 \times 10^{4} \mu \mathrm{g} \cdot \mathrm{mL}^{-1}$ were incubated in a 96 -well microtiter plate $(100 \mu \mathrm{L}$ in every well) for $24 \mathrm{~h}\left(37^{\circ} \mathrm{C}, 5 \% \mathrm{CO}_{2}\right)$. Then the cells were incubated continuously for $72 \mathrm{~h}$ following various concentrations of test drugs were added. The concentrations are $50 \mu \mathrm{M}, 10 \mu \mathrm{M}, 2 \mu \mathrm{M}, 0.4 \mu \mathrm{M}$, $0.08 \mu \mathrm{M}, 0.016 \mu \mathrm{M}, 0.0032 \mu \mathrm{M}$, respectively. After the $100 \mu \mathrm{L} 0.05 \%$ MTT solution was added to each well, the plate was incubated for a further $4 \mathrm{~h}$ before removal of medium, the media removed. Formazan crystals were dissolved with $100 \mu \mathrm{L}$ DMSO, then the absorbance was detected at $490 \mathrm{~nm}$.

\subsection{Acetylcholinesterase Inhibition Assay}

The AChE inhibition by all compounds was studied according to a modification of the method of Ellman et al. [15]. The activity was assayed with AChE from electric eel in the presence or absence of the test compounds in phosphate buffer (pH7.3). After the incubation at $37{ }^{\circ} \mathrm{C}$ for $1 \mathrm{~min}, 0.38 \mathrm{mM}$ 5,5-dithiobisnitrobenzoic acid and $0.56 \mathrm{mM}$ ATCh were added to the buffer. The changes in absorbance were read at $412 \mathrm{~nm}$, per $15 \mathrm{~s}$ intervals for $3 \mathrm{~min}$ by a spectrophotometer (UV-2500, Shimadzu Corp., Kyoto, Japan).

\subsection{Stability Test}

The stability of all compounds was investigated in PBS and human plasma by HPLC using a C18 analytical column. The mobile phase was composed of water and acetonitrile at a ratio of 70:30, respectively, containing 1\% trifluoroacetic acid. The amount of the compound and its metabolite SN-38 were flowed at the rate of $0.8 \mathrm{~mL} \cdot \mathrm{min}^{-1}$ and detected by the UV wavelength of $370 \mathrm{~nm}$. Stability test in PBS: each compound was dissolved in PBS (pH 7.4 and $\mathrm{pH} 4.6$ ), incubated at $37{ }^{\circ} \mathrm{C}$ and analyzed at 1 , $3,6,12 \mathrm{~h}$. Stability test in plasma: The test compounds were dissolved in DMSO and diluted to $1 \mathrm{mM}$ by $0.9 \%$ physiological saline. Forty $\mu \mathrm{L}$ of each solution was added into plasma with a final concentration of $0.1 \mathrm{mM}$. The mixture was incubated in a $37^{\circ} \mathrm{C}$ water bath following the vigorous vortex mixing for $15 \mathrm{~s}$. Samples were analyzed at 1, 3, 6, $12 \mathrm{~h} .400 \mu \mathrm{L}$ of cold acetonitrile (containing $1 \%$ trifluoroacetic acid) was added to each sample, vortex-mixed for $15 \mathrm{~s}$ and centrifuged at $3500 \mathrm{rpm}$ for $15 \mathrm{~min}$ at $4{ }^{\circ} \mathrm{C}$.

\section{Conclusions}

In summary, 14 novel SN-38 prodrugs were prepared by conjugating amino acids or dipeptides to the 10-hydroxy group of SN-38 via a carbamate linkage. These prodrugs were found to have much greater antitumor activities than SN-38. The synthesized compounds completely regenerated SN-38 in pH 7.4 buffer or in human plasma, so higher antitumor activity and less interpatient pharmacokinetic variability than with irinotecan treatment are expected. The ability of these prodrugs to inhibit AChE activity was also significantly reduced; thus, the administration of these compounds should cause less severe side effects owing to their diminished inhibition of AChE.

\section{Supplementary Materials}

Supplementary materials can be accessed at: http:/www.mdpi.com/1420-3049/19/12/19718/s1. 


\section{Acknowledgments}

This work was supported by a National Science and Technology Major Project of China grant (2012ZX09301003-001-004).

\section{Author Contributions}

B.Z., W.S. and X.H. conceived the the project, M.Z. and M.L. designed the experiments and executed the chemical synthesis. D.W., H.Y. and M.Z. performed the biological assays. M.L., M.Z. and P.Z. wrote the paper and S.F and Y.Y. edited English language. All authors discussed the results and commented on the manuscript.

\section{Conflicts of Interest}

The authors declare no conflict of interest.

\section{References}

1. Ohwada, J.; Ozawa, S.; Kohchi, M. Synthesis and biological activities of a pH-dependently activated water-soluble prodrug of a novel hexacyclic camptothecin analog. Bioorg. Med. Chem. Lett. 2009, 19, 2772-2776.

2. Basili, S.; Moro, S. Novel camptothecin derivatives as topoisomerase I inhibitors. Expert Opin. Ther. Patents 2009, 19, 555-574.

3. Hecht, J.R. Current and emerging therapies for metastatic colorectal cancer: Applying research findings to clinical practice. Am. J. Health Syst. Pharm. 2008, 65, S15-S21.

4. Langer, C.J. The global role of irinotecan in the treatment of lung cancer: 2003 Update. Oncology 2003, 17, 30-40.

5. Vredenburgh, J.J.; Desjardins, A.; Reardon, D.A.; Friedman, H.S. Experience with irinotecan for the treatment of malignant glioma. Neuro. Oncol. 2009, 11, 80-91.

6. Anthoney, D.A.; Naik, J.; Twelves, C. Phase I study of TP300 in patients with advanced solid tumors with pharmacokinetic, pharmacogenetic and pharmacodynamic analyses. BMC Cancer 2012, 12, 536-545.

7. Senter, P.D.; Beam, K.S.; Mixan, B.; Wahl, A.F. Identification and activities of human carboxylesterases for the activation of CPT-11, a clinically approved anticancer drug. Bioconjug. Chem. 2001, 12, 1074-1080.

8. De Jong, F.A.; Mathijssen, R.H.J.; Xie, R.; Verweij, J.; Sparreboom, A. Flat-fixed dosing of irinotecan: Influence on pharmacokinetic and pharmacodynamic variability. Clin. Cancer Res. 2004, 10, 4068-4071.

9. Endo, M.; Ohwada, J.; Ogawa, K.; Yamada-Okabe, H. A water soluble prodrug of a novel camptothecin analog is efficacious against breast cancer resistance protein-expressing tumor xenografts. Cancer Chemother. Pharmacol. 2010, 65, 363-371.

10. Hecht, J.R. Gastrointestinal toxicity or irinotecan. Oncology 1998, 12, 72-78.

11. Dodds, H.M.; Rivory, L.P. The mechanism for the inhibition of acetylcholinesterases by irinotecan (CPT-11). Mol. Pharmacol. 1999, 56, 1346-1353. 
12. Hyatt, J.L.; Tsurkan, L.; Morton, C.L.; Yoon, K.J.P.; Harel, M.; Brumshtein, B.; Silman, I.; Sussman, J.L.; Wadkins, R.M.; Potter, P.M. Inhibition of acetylcholinesterase by the anticancer prodrug CPT-11. Chem. Biol. Interact. 2005, 157-158, 247-252.

13. Sussman, J.L.; Harel, M.; Frolow, F.; Oefner, C.; Goldman, A.; Toker, L.; Silman, I. Atomic structure of acetylcholinesterase from Torpedo californica: A prototypic acetylcholine-binding protein. Science 1991, 253, 872-879.

14. Harel, M.; Hyatt, J.L.; Brumshtein, B.; Morton, C.L.; Yoon, K.J.P.; Wadkins, R.M.; Silman, I.; Sussman, J.L.; Potter, P.M. The crystal structure of the complex of the anticancer prodrug 7-ethyl-10-[4-(1-piperidino)-1-piperidino]-carbonyloxycamptothecin (CPT-11) with Torpedo californica acetylcholinesterase provides a molecular explanation for its cholinergic action. Mol. Pharmacol. 2005, 67, 1874-1881.

15. Ellman, G.L.; Courtney, K.D.; Anders, V.; Feather-Stone, R.M. A new and rapid colorimetric determination of acetylcholinesterase activity. Biochem. Pharmacol. 1961, 7, 88-95.

Sample Availability: Samples of the compounds are available from the authors.

(C) 2014 by the authors; licensee MDPI, Basel, Switzerland. This article is an open access article distributed under the terms and conditions of the Creative Commons Attribution license (http://creativecommons.org/licenses/by/4.0/). 